\title{
An overview of Brazilian mammalogy: trends, biases and future directions
}

\author{
Daniel Brito 1, 5; Leonardo C. Oliveira 2; Monik Oprea ${ }^{3} \&$ Marco A. R. Mello ${ }^{4}$
}

\author{
1 Departamento de Biologia Geral, Instituto de Ciências Biológicas, Universidade Federal de Goiás. Caixa Postal 131, \\ 74001-970 Goiânia, Goiás, Brasil. Email: brito.dan@gmail.com \\ 2 University of Maryland, Department of Biology, College Park, MD 20740, USA. \\ ${ }^{3}$ Smithsonian Institution, National Museum of Natural History, Division of Mammals, Washington, DC 20013, USA. \\ ${ }^{4}$ Departamento de Botânica, Universidade Federal de São Carlos. Rodovia Washington Luís, km 235, 13565-905 São \\ Carlos, São Paulo, Brasil. \\ ${ }^{5}$ Corresponding author.
}

\begin{abstract}
Mammals are among the most charismatic and well-studied organisms, and Brazil harbors the largest mammal diversity of the world. The Brazilian Society of Mammalogy was established in 1985, and since 2001 it organizes the Brazilian Congress of Mammalogy. We used the proceedings of all three editions of this congress together with papers indexed in Web of Science and Scielo to evaluate trends in Brazilian mammalogy. All contributions were categorized according to mammalian order, biome, topic of research and state of authors' affiliation. Our results show that mammalian orders with higher species richness receive more attention, but the ranking is different between abstracts and papers. Higher species richness did not translate into more attention for more speciose biomes, and again the ranking was different between papers and abstracts. There are research topics that receive much higher attention than others, and also other important ones, like Taxonomy, that have been neglected. States with greater human populations produce both more papers and abstracts. We conclude that the higher number of publication in the Atlantic Forest is caused by the concentration of mammalogists in the south and southeastern regions of the country. Contrary to what is normally believed, mammalian orders received attention according to their species richness, and not their charisma, probably because richer orders provide more study models. We suggest that additional funding mechanisms should be set in place in order to encourage more research on mammalian orders, topics, and states which have been neglected so far, in order to improve the knowledge on important Brazilian mammal biodiversity.
\end{abstract}

KEY WORDS. Biomes; meta-analysis; priorities; scientometrics.

Mammals are one of the best-studied groups of living organisms, and important areas and countries with the largest number of threatened species have already been identified (COLE et al. 1994, Ceballos \& Brown 1995, Baillie et al. 2004, Cardillo et al. 2006, Ceballos \& Ehrlich 2006, Iucn 2007). Mammalian species diversity and endemism have been used with measures of recent rates of habitat loss, human population growth, and density parameters to identify global threats to biodiversity (SISK et al. 1994). However many gaps still exist in our knowledge of mammals in some tropical regions (SCHALLER 1996).

This is true and particularly worrisome for Brazil, a megadiverse country (Mittermeier et al. 1997) with two biodiversity hotspots (Atlantic Forest and Cerrado) (Myers et al. 2000, Mittermeier et al. 2005) and three wilderness areas (Amazon, Caatinga and Pantanal) (MitTermeier et al. 1998, 2002, 2003). The country harbors the largest mammal diversity in the world with a total of 652 species (ReIs et al. 2006), representing approximately $12 \%$ of all living mammals worldwide (Wilson \& ReEder 2005). The levels of endemism are also very high, with approximately $25 \%$ of the mammal species recorded for the country being endemics (Fonseca et al. 1996). Approximately $11 \%$ of the mammal species found in Brazil are listed as globally threatened by IUCN (IUCN 2007) and 10\% as nationally threatened by the Brazilian National Red List (MACHADO et al. 2005). Two threatened mammals in Brazil (Callicebus barbarabrownae and Callicebus coimbrai) declined to only one population and are listed by the Alliance for Zero Extinction (RicketTs et al. 2005). Brazil is also one of the regions of the world that contributes most with the description of new mammalian species (REeDer et al. 2007), what indicates a greater diversity than currently known.

There are several scientific societies dedicated to the study of mammals worldwide, and the Brazilian Society of Mammalogy (SBMz) was established in 1985 (CERQueira 2005). In 2001, SBMz organized the First Brazilian Congress of Mammalogy $(\mathrm{CBMz})$, an event that since then had two other editions in 2003 and 2005. An analysis both of abstracts published in the proceedings of the CBMzs and papers indexed in Web of Sci- 
ence and Scielo in the same period offers a good and representative sample of how Brazilian mammalogists allocate their research efforts. Therefore, in the present study we aimed to understand trends and biases in Brazilian mammalogy, in order to evaluate whether its efforts have been well applied, and what future changes are needed. We answered the following questions: (1) are there differences in the number of papers and abstracts among mammalian orders, biomes, research topics and states, evidencing a differential allocation of efforts? (2) Are the patterns of attention different between papers and abstracts, considering that not all congress presentations become published articles? (3) Do richer orders and biomes receive more attention, considering that they provide more study models? (4) Considering population size as a surrogate for number of mammalogists, do more populous states generate more research?

\section{MATERIAL AND METHODS}

We surveyed the proceedings of the first, second, and third Brazilian Congresses of Mammalogy (SвMz 2001, 2003, 2005). Not all studies presented in a congress and published as proceedings come to the final stage of being published in a scientific journal. Therefore, we also decided to analyze articles published between 2000 and 2005, representing research carried out in Brazil. In order to analyze the published articles, we collected information from the global database Web of Science (http://portal.isiknowledge.com) and the Latin-American database Scielo (http://www.scielo.br). Only papers published in the 2000-2005 period were included in the analysis. We obtained the number of mammalian species in each order and biome from ReIs et al. (2006).

In order to answer our first question, we grouped data from abstracts published in all three editions of CBMz according to mammalian order, biome, research topic and state. According to ReIs et al. (2006), there are 12 mammal orders occurring in Brazil: Artiodactyla, Carnivora, Cetacea, Chiroptera, Cingulata, Didelphimorphia, Lagomorpha, Perissodactyla, Pilosa, Primates, Rodentia and Sirenia. All proceedings abstracts and published articles were categorized according to the mammal order studied, and studies that evaluated more than one order were grouped in a category labeled general. We considered that Brazil has six main biomes within its borders: Amazon Forest, Atlantic Forest, Caatinga, Cerrado, Marine and Pantanal. We categorized research topics into Anatomy/Morphology, Behavior, Biogeography/Distribution, Conservation, Ecology, Evolution, Genetics, Health, Inventory/Survey, Management, Museums/Zoos, Paleontology, Physiology, Systematics/Taxonomy and Techniques. For the analysis evaluating the author's affiiations, we used the official division of the Brazilian territory in 26 states and one federal district. We tested for differences among categories with a $\chi^{2}$ test (ZAR 1996).

In order to address our second question, we separated data into abstracts and papers in the four groups of categories mentioned before (orders, biomes, topics and states). Then we tested for differences in their frequency distributions with Wilcoxon's Z test (ZAR 1996).

We answered our third question by calculating a quadratic regression between the number of species (independent variable) and the number of publications (response variable) in a given order or biome (ZAR 1996). The reason for choosing a nonlinear model was the high differences among categories in both cases (orders and biomes).

Finally, to answer our fourth question, we calculated a linear regression between the human population size (independent variable) and the number of publications (response variable) in each Brazilian state. We used human population size, obtained from the last national census (IbGe 2007), as a surrogate of the number of mammalogists in a given state.

\section{RESULTS}

Our results suggest that Brazilian mammalogy research efforts are not evenly distributed among mammal orders $\left(\chi^{2}=1225.79, \mathrm{p}<0.001\right.$, Fig. 1$)$, biomes $\left(\chi^{2}=1642.23, \mathrm{p}<0.001\right.$, Fig. 2), research topics $\left(\chi^{2}=1716.68, p<0.001\right.$, Fig. 3$)$ and states $\left(\chi^{2}=4387.82, p<0.001\right.$, Fig. 4$)$.

Ecology is the preferred research topic both for abstracts and articles (Fig. 3). However there is a noticeable difference between the number of abstracts and the number of published articles, suggesting that most of the research appearing in $\mathrm{CBMz}$ abstracts do not make it into the scientific literature. Inventory/survey is the second most common research topic in abstracts, but almost no article is published on the topic (Fig. 3). For inventory/survey a pattern similar to the one observed for ecology (see above) is noted, suggesting that most of the abstracts do not become real publications (Fig. 3). The opposite occurs in the topic Evolution, with a good number of published articles, but very little presence among abstracts (Fig. 3).

More abstracts $\left(\mathrm{r}^{2}=0.89, \mathrm{p}<0.001, \mathrm{~N}=12\right.$, Fig. 5) and articles $\left(\mathrm{r}^{2}=0.68, \mathrm{p}=0.006, \mathrm{~N}=12\right.$, Fig. 6$)$ are published for mammalian orders that have more species. Some orders received more papers than expected, especially the Sirenia, Chiroptera and Primates (Fig. 6). However, the preferred orders in abstracts were different: Carnivora, Rodentia and Didelphimorphia (Fig. 5). Species richness within a biome explains neither the number of papers $\left(\mathrm{r}^{2}=0.52, \mathrm{p}=0.33, \mathrm{~N}=6\right.$, Fig. 7) nor the number of abstracts $\left(\mathrm{r}^{2}=0.33, \mathrm{p}=0.55, \mathrm{~N}=6\right.$; Fig. 8) that have been produced in it. Nonetheless, as seen in figure 1 , the number of publications resulting from studies carried out in the Atlantic Forest is higher than publications in other biomes.

States that have a larger population size produce more papers $\left(\mathrm{r}^{2}=0.37, \mathrm{p}<0.001\right.$, Fig. 9) and also more abstracts $\left(\mathrm{r}^{2}=\right.$ $0.45, \mathrm{p}<0.001$, Fig. 10). We observed that most Brazilian mammalogical research is carried out in the states of Rio de Janeiro and São Paulo (Figs 4, 9 and 10), both in the southeastern region. 

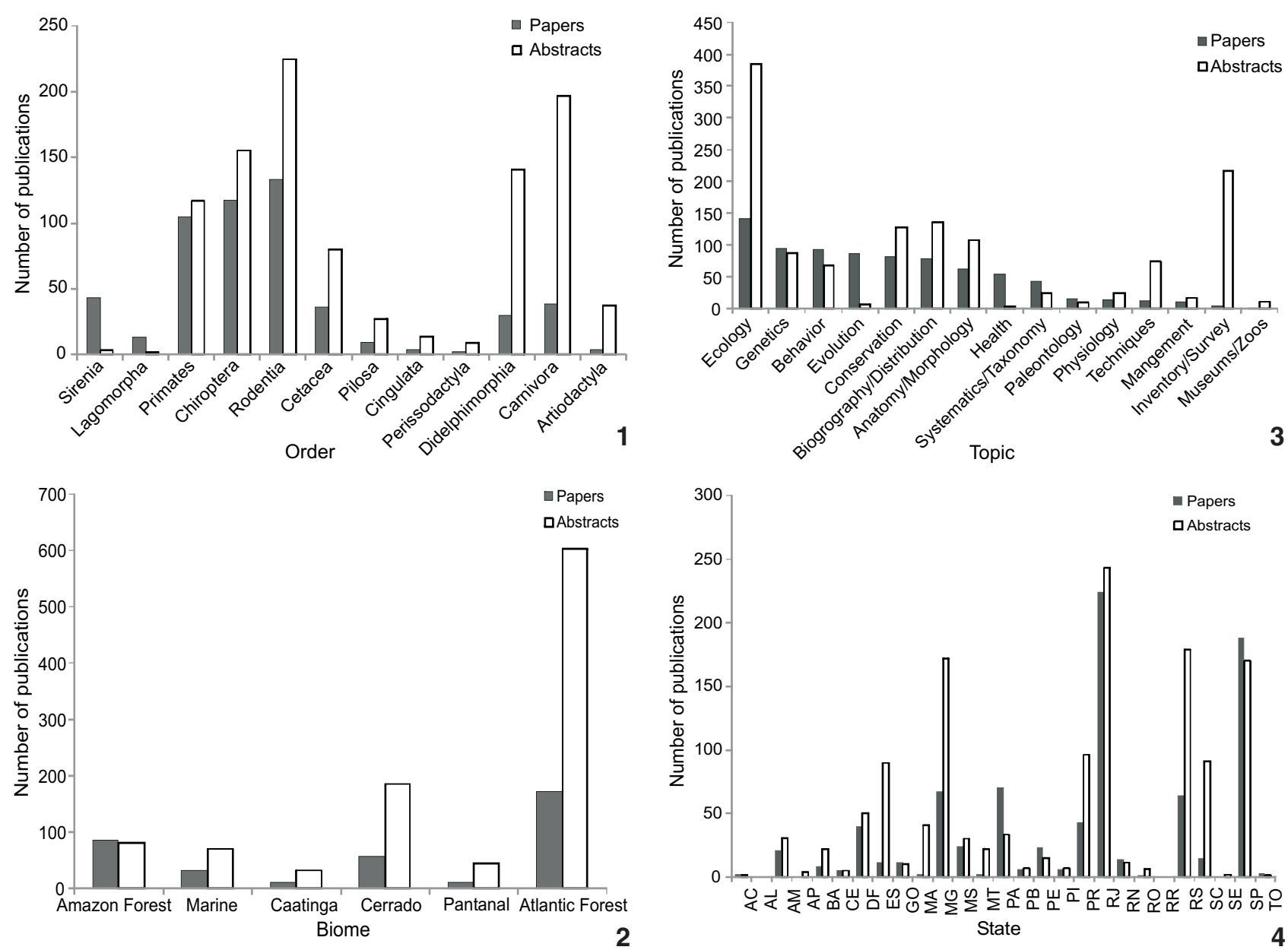

Figures 1-4. Distribution of publications (papers and abstracts) according to (1) mammalian order, (2) biome, (3) research topic and (4) state in Brazil between 2000 and 2005.

\section{DISCUSSION}

In our study, we observed important trends and biases in Brazilian mammalogy. There are many differences in the allocation of research to different mammalian orders and biomes. There are also some neglected research topics. Finally, the concentration of researchers in the south and southeastern regions of the country seems to be the reason for the concentration of most studies in the Atlantic Forest.

First, there were some unexpected biases in the attention given to different mammalian orders. It was expected that the most charismatic orders, like the Primates and Cetacea, would be the target of most publications. However, the productivity of a given order was best explained by its species richness. The most diverse mammal orders in Brazil are Rodentia and Chiroptera (ReIs et al. 2006). Together with primates, they also have the greatest absolute number of threatened species (IUCN 2007), but Sirenia and Perissodactyla have the greatest proportion of threatened species (IUCN 2007). However, these results for Sirenia and Perissodactyla are biased due to the small total number of species in these orders. Brazilian mammalogists should pay more attention to orders that are poorly-known and in greater threat. It is also noticeable that some orders (e.g. Didelphimorphia, Rodentia and Carnivora) present a relatively large gap between the number of abstracts and the number of articles (Fig. 1), suggesting that most of the research appearing on the $\mathrm{CBMz}$ abstracts do not make into the published scientific literature.

The Amazon is the largest biome in Brazil with the largest number of species and endemics, following the species-area biogeographic relationship (FonseCA et al. 1999). This is probably the most diverse region in the world in terms of vertebrates (Voss \& Emmons 1996). Nevertheless, our results show that it receives less than expected attention. The Atlantic Forest ranks second in mammal diversity, and has more species and endemics than expected by its area (Fonseca et al. 1999), 

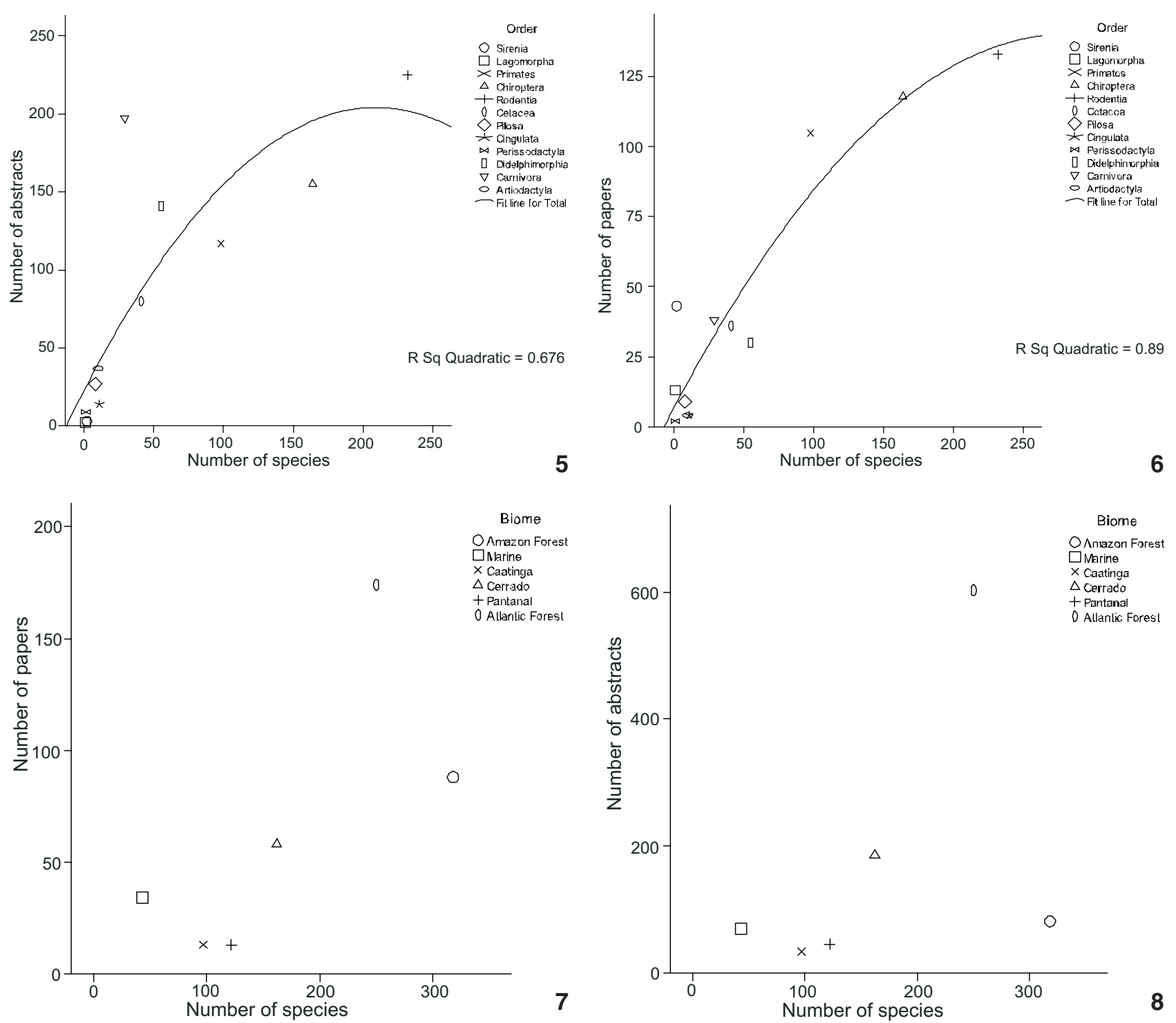

Figures 5-8. Relationship between the number of publications and the number of species for each mammalian order (5: abstracts, 6: papers) and biome (7: papers, 8: abstracts) in Brazil between 2000 and 2005.

whereas the Cerrado and the Caatinga biomes have less species and endemics than expected (FonsECA et al. 1999). Biases in the attention given to biomes are also worrisome. One of the possible causes for this bias in mammal studies in different biomes may arise because the great majority of Brazilian mammalogists and research institutions are located in the south and southeastern regions of the country, exactly within the Atlantic Forest biome. Another possible cause for the higher number of studies in the Atlantic Forest may be due to the conservation efforts to preserve threatened species, ecosystem processes and habitat in one of the most threatened ecoregions of the world (Myers et al. 2000, Mittermeier et al. 2005). Brazilian mammalogists should allocate larger research efforts in poorlyknown biomes, like the Caatinga, because we need to have a more complete picture of the national mammal fauna in order to propose and establish efficient research and conservation strategies and policies. In order for Brazil to properly study its mammal diversity, it is important that incentives and opportunities to attract and settle mammalogists in other states and regions are implemented; this is particularly important for north, mid-west and northeastern Brazil.

The Brazilian biomes with greater percentage of threatened mammals are (from greater to lower): marine, Atlantic Forest, Cerrado, Pantanal, Amazon and Caatinga (Costa et al. 

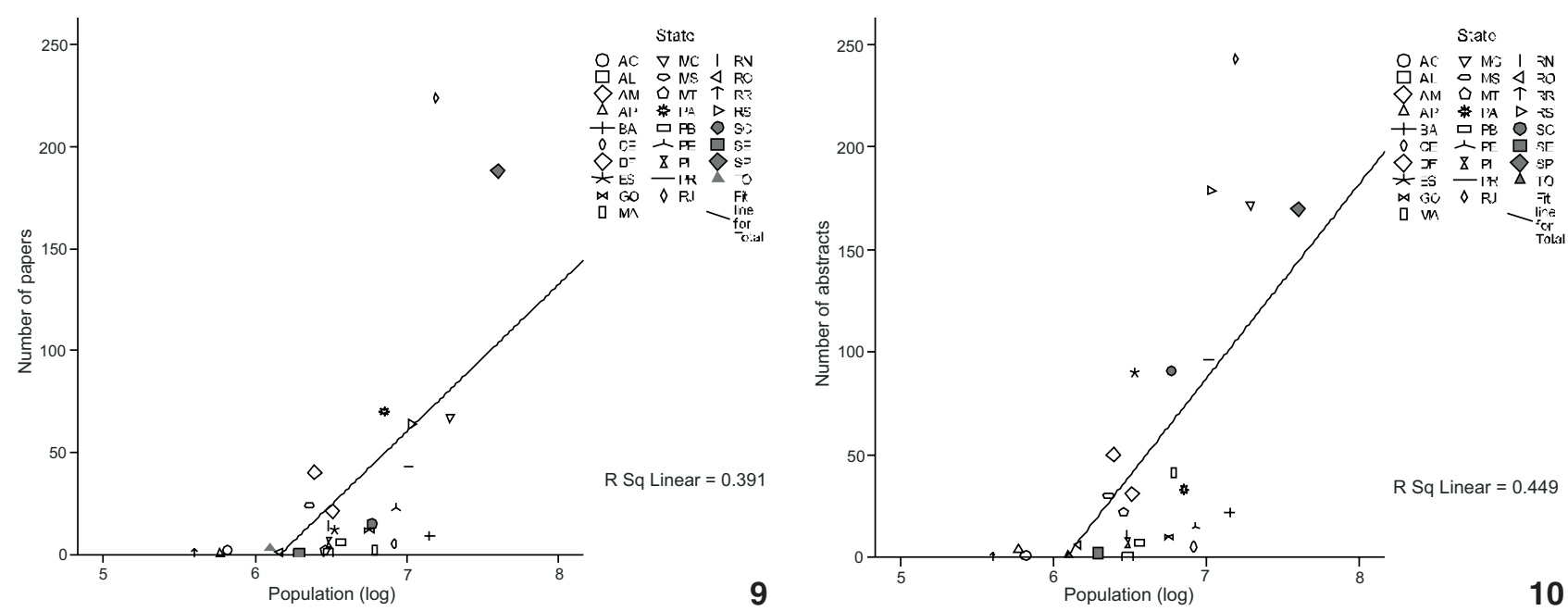

Figures 9-10 Relationship between the population size (log) and the number of papers (9) and abstracts (10) in each Brazilian state between 2000 and 2005 .

2005, Machado et al. 2005). Studies using species-area relationships of mammals, as a predictor of extinction proneness, concluded that mammals are more affected by deforestation than reptiles and amphibians in the Atlantic Forest (Grelle et al. 1999, 2005). The predicted extinction as a function of habitat loss, in the Atlantic Forest and in the Cerrado, is found to be greater than the number of taxa actually listed as threatened, whereas the reverse was observed for the Amazon (Grelle et al. 1999). However, taking into account predicted habitat loss due to development projects for the Amazon (LAurance et al. 2001), Grelle (2005) used species-area relationships to show that the percentage of endemic Amazonian mammals threatened by extinction due to habitat loss may increase between two and three times the present values and encompass between 5-18\% of the total number of endemic mammals.

Although ecology and inventories $\backslash$ surveys are important research topics, the Brazilian mammalogical community should also invest in other research areas, especially in taxonomy, which is terribly underrepresented in the international scientific production. We need urgently to promote the increase in the number of taxonomists, because the identification and classification of species is the base of all other biological research, and Brazil is facing a serious shortage of mammal taxonomists. This shortage may have serious consequences for research and conservation efforts in the country (BRITO 2004). In the fields of ecology and inventories/surveys, Brazilian mammalogists should plan their studies taking into account in more global perspectives and general theoretical frameworks, in order to better understand how Brazilian mammalian patterns and processes fit into a global picture. We should be also pay a higher attention to management studies, in order to solve urgent problems involving both wild and sinantropic species.

The Brazilian $\mathrm{CBMz}$ is an important national forum for discussion and diffusion of knowledge in the country. An important issue is to question why most of the research that appears as poster and oral presentations in the congress do not proceed to become a formal publication in scientific journals. Also, in order to improve the role of Brazilian mammalogy in producing scientific knowledge and providing information for conservation of Brazilian biodiversity, and in diminish the gap of knowledge and research, we suggest that the event should always rotate among regions and states in Brazil. This could help to integrate researchers from different regions, who could find out common interests and join their efforts. So far the three events took place in southern and southeastern Brazil, and the fourth edition is going to take place again in the southeastern region, and both regions have already most of the attention by Brazilian mammalogists. This way, the event would be more representative of the environmental diversity, political realities and author diversity in Brazil, and would improve its role in promoting not only knowledge dissemination, but also in directing research for poorly-studied taxa and ecosystems and better helping the ultimate goal of preserving mammal diversity in one of the most biologically rich countries in the world. Our results provide a first general overview of mammal science in Brazil, and they clearly show its trends and biases, helping us identify and better plan and direct future mammal research priorities, both on a taxonomic, thematic and geographic scope. Our results also show the importance for mammalogists to publish the results of their research in easily accessible venues. Two decades after its formal birth, Brazilian mammalogy is mature enough to look upon itself, evaluate its achievements, learn from its mistakes, and establish priorities through scientific planning, and the use of scientometric analyses may be a useful tool in helping guide the future of mammalogy in Brazil. 


\section{ACKNOWLEDGMENTS}

We thank Don E. Wilson, who provided comments and suggestions in an earlier version of the manuscript. We also would like to thank Fernando Passos, Helena Bergallo and two anonymous referees, who gave valuable comments and suggestions that substantialy improved the manuscript.

\section{LITERATURE CITED}

Baillie, J.E.M.; C. Hilton-Taylor \& S.N. Stuart. 2004. A global species assessment. Gland, IUCN, 191p.

BRITO, D. 2004. Lack of adequate taxonomic knowledge may hinder endemic mammal conservation in the Brazilian Atlantic Forest. Biodiversity and Conservation 13: 2135-2144.

Cardillo, M.; G.M. Mace; J.L. Gittleman \& A. Purvis. 2006. Latent extinction risk and future battlegrounds of mammal conservation. Proceedings of the National Academy of Sciences of the United States of America 103: 4157-4161.

Ceballos, G. \& J.H. Brown. 1995. Global patterns of mammalian diversity, endemism and endangerment. Conservation Biology 9: 559-568.

Ceballos, G. \& P.R. Ehrlich. 2006. Global mammal distributions, biodiversity hotspots, and conservation. Proceedings of the National Academy of Sciences of the United States of America 103: 19374-19379.

Cerqueira, R. 2005. 20 anos da Sociedade Brasileira de Mastozoologia, p 9. In: SBMz (Ed.). Livro de Resumos do III Congresso Brasileiro de Mastozoologia. Aracruz, Sociedade Brasileira de Mastozoologia, 150p.

Cole, F.R.; D.M. Reeder \& D.E. Wilson. 1994. A synopsis of distribution patterns and the conservation of mammal species. Journal of Mammalogy 75: 266-277.

Costa, L.P.; Y.L.R. Leite; S.L. Mendes \& A.D. Ditchfield. 2005. Mammal conservation in Brazil. Conservation Biology 19: 672-679.

Fonseca, G.A.B.; G. Herrmann; Y.R.L. Leite; R.A. Mittermeier; A.B. Rylands \& J.L. Patton. 1996. Lista anotada dos mamíferos do Brasil. Occasional Papers in Conservation Biology 4: 1-38.

FonseCA, G.A.B.; G. HeRrManN \& Y.L.R. LeITE. 1999. Macrogeography of Brazilian mammals, p. 549-563. In: EIsenberG J.F. \& K.H. REDFORD (Eds). Mammals of the Neotropics: the central Neotropics. Chicago, University of Chicago Press, vol. 3, 624p.

Grelle, C.E.V. 2005. Predicting extinction of mammals in the Brazilian Amazon. Oryx 39: 347-350.

Grelle, C.E.V.; G.A.B. Fonseca; M.T. Fonseca \& L.P. Costa. 1999. The question of scale in threat analysis: a case study with Brazilian mammals. Animal Conservation 2: 149-152.

Grelle, C.E.V.; M.A.S. Alves; H.G. Bergallo; L. Geise; C.F.D. RoCha; M. van Sluys \& U. Caramaschi. 2005. Prediction of threatened tetrapods based on the species-area relationship in Atlantic Forest, Brazil. Journal of Zoology 265: 359-364.

IBGE. 2007. Contagem da população 2007. Brasília, Instituto Brasileiro de Geografia e Estatística, 311p.
IUCN. 2007. 2007 IUCN Red List of threatened species. World Conservation Union, available online at: http://www.iucn redlist.org/ [Access: 01/IV/2008].

Laurance, W.F.; M.A. Cochrane; S. Bergen; P.M. Fearnside; P. DelaMÔNICA; C. BARber; S. D'Angelo \& T. Fernandes. 2001. The future of the Brazilian Amazon. Science 291: 438-439.

Machado, A.B.M.; C.S. Martins \& G.M. Drummond. 2005. Lista da fauna brasileira ameaçada de extinção. Belo Horizonte, Fundação Biodiversitas, 160p.

Mittermeier, R.A.; P. Gil \& C.G. Mittermeier. 1997. Megadiversity: Earth's biologically wealthiest nations. Mexico, CEMEX, 501p.

Mittermeier, R.A.; N. Myers; J.B. Thomsen; G.A.B. Fonseca \& S. OLIVIERI. 1998. Biodiversity hotspots and major tropical wilderness areas: approaches to setting conservation priorities. Conservation Biology 12: 516-520.

Mittermeier, R.A.; C.G. Mittermeier; P.R. Gil; J. Pilgrim; G.A.B. Fonseca; T. BRoOKs \& W.R. Konstant. 2002. Wilderness: Earth's last wild places. Mexico, CEMEX, 576p.

Mittermeier, R.A.; C.G. Mittermeier; T.M. Brooks; J.D. Pilgrim; W.R. Konstant; G.A.B. da Fonseca \& C. Kormos. 2003. Wilderness and biodiversity conservation. Proceedings of the National Academy of Sciences of the United States of America 100: 10309-10313.

Mittermeier, R.A.; P.R. Gil; M. Hoffmann; J. Pilgrim; T. Brooks; C.G. Mittermeier; J. Lamoreux \& G.A.B. Fonseca. 2005. Hotspots revisited: Earth's biologically richest and most endangered terrestrial ecoregions. Mexico, CEMEX, 392p.

Myers, N.; R.A. Mittermeier; C.G. Mittermeier; G.A.B. Fonseca \& J. Kent. 2000. Biodiversity hotspots for conservation priorities. Nature 403: 853-858.

Reeder D.M.; K.M. Helgen \& D.E. Wilson. 2007. Global trends and biases in new mammal species discoveries. Occasional Papers of the Museum of Texas Tech University 269: 1-34.

Reis, N.R.; O.A. Shibata; A.L. Peracchi; W.A. Pedro \& I.P Lima. 2006. Sobre os Mamíferos do Brasil, p. 17-24. In: N.R. Reis; A.L. Peracchi; W.A. Pedro \& I.P. Lima (Eds). Mamíferos do Brasil. Londrina, Universidade Estadual de Londrina, 437p.

Ricketts, T.H.; E. Dinerstein; T. Boucher; T.M. Brooks; S.H.M. Butchart; M. Hoffmann; J.F. Lamoreux; J. Morrison; M. Parr; J.D. Pilgrim; A.S.L. Rodrigues; W. Sechrest; G.E. Wallace; K. Berlin; J. Bielby; N.D. Burgess; D.R. Church; N. Cox; D. Knox, C. Loucks; G.W. Luck; L.L. Master; R. Moore; R. Naidoo; R. Ridgely; G.E. Schatz; G. Shire; H. Strand; W. Wettengel \& E. WiKRAMANAYAKE. 2005. Pinpointing and preventing imminent extinctions. Proceedings of the National Academy of Sciences of the United States of America 102: 18497-18501.

SBmz. 2001. Livro de Resumos do I Congresso Brasileiro de Mastozoologia. Porto Alegre, Sociedade Brasileira de Mastozoologia, 173p.

Sвmz. 2003. Livro de Resumos do II Congresso Brasileiro de Mastozoologia. Belo Horizonte, Sociedade Brasileira de Mastozoologia, 299p. 
Sвмz. 2005. Livro de Resumos do III Congresso Brasileiro de Mastozoologia. Aracruz, Sociedade Brasileira de Mastozoologia, 150p.

SCHALLER, G.B. 1996. Introduction: carnivores and conservation biology, p. 1-10. In: J.L. GITTLEMAN (Ed.). Carnivore behavior, ecology and evolution. Ithaca, Cornell University Press, 620p.

Sisk, T.D.; A.E. Launer; K.R. Switky \& P.R. Ehrlich. 1994. Identifying extinction threats. BioScience 44: 592-604.
Voss, R. \& L.H. Emmons. 1996. Mammalian diversity in Neotropical lowland rainforest: a preliminary assessment. Bulletin of the American Museum of Natural History 230: 1-115. Wilson, D.E. \& D.A. Reeder. 2005. Mammal species of the world: a taxonomic and geographic reference. Baltimore, Johns Hopkins University Press, 2000p.

ZAR J.H. 1996. Biostatistical analysis. New Jersey, Prentice Hall, 929p.

Submitted: 22.V.2008; Accepted: 12.III.2009.

Editorial responsibility: Fernando Camargo Passos 